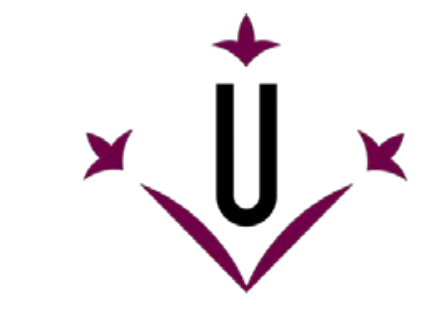

Universitat de Lleida

Document downloaded from:

http://hdl.handle.net/10459.1/59461

The final publication is available at:

https://doi.org/10.1021/acs.analchem.6b02961

Copyright

(c) American Chemical Society, 2016 
This document is confidential and is proprietary to the American Chemical Society and its authors. Do not copy or disclose without written permission. If you have received this item in error, notify the sender and delete all copies.

\section{Accumulation of Mg to Diffusive Gradients in Thin Films (DGT) devices: kinetic and thermodynamic effects of the ionic strength}

\begin{tabular}{|r|l|}
\hline Journal: & Analytical Chemistry \\
\hline Manuscript ID & ac-2016-02961v.R1 \\
\hline Manuscript Type: & Article \\
\hline Date Submitted by the Author: & n/a \\
\hline Complete List of Authors: & $\begin{array}{l}\text { Altier, Alexandra; Universitat de Lleida, Departament de Quimica } \\
\text { Jiménez-Piedrahita, Martín; Universitat de Lleida, Departament de Quimica } \\
\text { Rey-Castro, Carlos; Universitat de Lleida, Chemistry } \\
\text { Cecilia, Joan; Universitat de Lleida, Matemàtica } \\
\text { Galceran, Josep; Universitat de Lleida, Chemistry } \\
\text { Puy, Jaume; Universitat de Lleida, Departament de Quimica }\end{array}$ \\
\hline
\end{tabular}




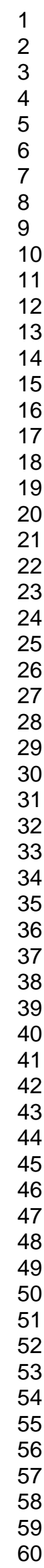

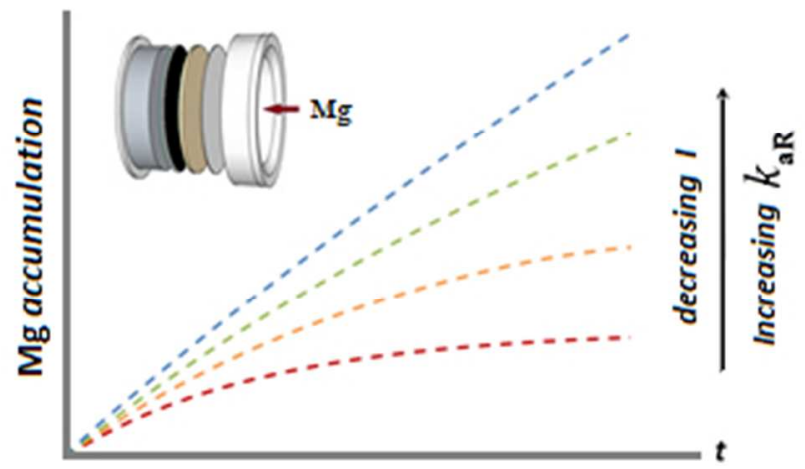

$84 \times 50 \mathrm{~mm}(96 \times 96 \mathrm{DPI})$ 


\title{
Accumulation of Mg to Diffusive Gradients in Thin Films (DGT) devices: kinetic and thermodynamic effects of the ionic strength
}

\author{
Alexandra Altiera ${ }^{a}$, Martín Jiménez-Piedrahita ${ }^{a}$, Carlos Rey-Castro ${ }^{a}$, Joan \\ Cecilia $^{\text {b }}$, Josep Galceran ${ }^{a}$, Jaume Puy ${ }^{\text {a* }}$ \\ ${ }^{\mathrm{a} D e p a r t a m e n t}$ de Química, ${ }^{\mathrm{b}}$ Departament de Matemàtica, Universitat de Lleida and \\ AGROTECNIO, Rovira Roure 191, 25198, Lleida, Spain \\ * Corresponding author. E-mail address: jpuy@quimica.udl.cat, Phone 34973 702529, Fax \\ 34973702924
}




\begin{abstract}
Availability of magnesium is a matter of concern due to its role in many environmental and biological processes. Diffusive Gradients in Thin Films (DGT) devices can measure $\mathrm{Mg}$ availability in situ. This work shows that $\mathrm{Mg}$ accumulation in waters largely increases when ionic strength $(I)$ decreases. This phenomenon can be explained from i) the increase of both the association equilibrium $(K)$ and rate $\left(k_{\mathrm{a}, \mathrm{R}}\right)$ constants for the reaction between $\mathrm{Mg}$ cations and resin sites, and ii) the growing contribution of the partitioning of $\mathrm{Mg}$ cations at the resin-gel interface, as $I$ decreases.

Two theoretical models, that take into account electrical interactions among $\mathrm{Mg}$ cations, background electrolyte and resin sites, can successfully be used to determine $k_{\mathrm{a}, \mathrm{R}}$ and $K$ at each $I$. Both models yield similar $k_{\mathrm{a}, \mathrm{R}}$ values which fulfil an expression for the kinetic salt effect. For freshwaters (with a typical salinity of $10 \mathrm{mM}$ and circumneutral $\mathrm{pH}$ ), the binding of $\mathrm{Mg}$ is so fast and strong that the simplest perfect-sink DGT expression can be helpful to predict (overestimation lower than 5\%) the accumulation in solutions with $\mathrm{Mg}$ concentrations up to $1 \mathrm{mM}$ whenever the deployment time is below $9 \mathrm{~h}$. Perfect sink conditions can still be applied for longer times, in systems with either a lower $I$ or a lower $\mathrm{Mg}$ concentration.
\end{abstract}




\section{INTRODUCTION}

Magnesium has many important roles in soils, sediments, minerals and waters ${ }^{1}$. In soils, divalent cation concentrations are important for soil compactation, structuration and plant growth. In waters, $\mathrm{Mg}$ is partially responsible for water hardness. Waters that contain divalent cations like $\mathrm{Mg}$ and dissolved organic matter (DOM) are known to be problematic in terms of membrane fouling ${ }^{2 ; 3}$, preventing the proper functioning of water supply systems or heat exchangers. $\mathrm{Mg}$ is also an essential nutrient affecting many physiological functions like the uptake of other nutrients, neurotransmission or immune functions and, in general, the functions of many enzymes ${ }^{4-6}$. Availability of $\mathrm{Mg}$ is, then, a subject of environmental concern, where topics like interactions with $\mathrm{DOM}^{7}$ as well as uptake mechanisms ${ }^{8}$ have received attention recently. In terms of environmental aquatic toxicology, the bioavailability and the affinity of metals to accumulate on surfaces of organisms depend on the site-specific water quality including parameters such as $\mathrm{pH}$, hardness and DOM concentration ${ }^{9}$. Reduction in the toxicity and accumulation of metals as a function of water hardness $(\mathrm{Ca}$ and $\mathrm{Mg})$ in freshwater has also been reported in some studies with the Biotic Ligand Model (BLM) ${ }^{10-12}$.

In the last decade, DGT devices have been recognized as suitable tools to measure in situ the availability of metals cations, anions and some emergent pollutants in soils and waters 13-16. Literature data for $\mathrm{Mg}$ accumulation in DGT devices is scarce and apparently inconsistent. For instance, Dahlqvist et al. ${ }^{17}$ reported linear accumulations with time, in agreement with the perfect-sink model, at ionic strengths $(I)$ below $1 \mathrm{mM}$ (as calculated from the test solution composition). On the other hand, Garmo et al, ${ }^{18}$, did not observe a linear uptake behaviour at $I=10 \mathrm{mM}$. 
The interpretation of the influence of the ionic strength of the deployment solutions on DGT data is still controversial, particularly in what regards the performance of the technique at low salinities. Some authors reported no influence of $I$ on the metal accumulation in synthetic solutions in absence of organic ligands ${ }^{19 ; 20}$. In systems where the metal speciation is dominated by the presence of an organic complex, however, variations of the metal accumulation with $I$ (depending on the lability of the complexes) have been described ${ }^{21}$. The effects of the ionic strength on the accumulation have been explained by different authors through a varying "effective" diffusion coefficient that includes ion migration phenomena ${ }^{22}$, by the use of an electrostatic partitioning at the gel-solution interface $^{23-25}$, or by the combination of electrostatic partitioning and changes on the resinmetal binding rate constants ${ }^{21}$. In the latter case, experimental evidence suggests that electrostatic partitioning at the resin-gel interface is dominant over that in the gel-solution interface, but kinetic effects are also needed to justify the salt background influence in DGT accumulations.

The free metal accumulation in the resin disc results from a reaction between two charged species. The kinetics of this reaction is usually so fast that the accumulation is limited by transport, as considered by the standard DGT model. By using DGT devices with a stack of two resin discs, this approximation has been shown to be valid for many cations whose accumulated mass in the back resin disc is negligible ${ }^{26}$. However, other cations diverge from this behaviour even at short times. In these cases, penetration of the free metal is due to slow binding or equilibrium effects, there is a non-null metal profile in the resin domain and the metal accumulation flux is not maximum.

The aim of this work is to discuss the availability of $\mathrm{Mg}$ to DGT devices providing evidences of the phenomena that limit Mg accumulation at each ionic strength. Two models 
which consider the electrostatic migration effects on the metal ions, as well as the variation of the kinetic and stability constants with the ionic strength, will be used for a quantitative characterisation of the $\mathrm{Mg}$ binding.

\section{EXPERIMENTAL SECTION}

DGT holders (piston type, $2 \mathrm{~cm}$ diameter window), polyacrylamide gel discs (diffusive disc, $0.8 \mathrm{~mm}$ thick, and Chelex resin disc, $0.4 \mathrm{~mm}$ thick) from DGT Research Ltd. were used. DGT devices were prepared as described elsewhere (See, for instance, SI of ${ }^{21}$ ). A 5 L polyethylene exposure chamber was thermostated at $25 \pm 0.1^{\circ} \mathrm{C}$ and stirred at $240 \mathrm{rpm}$. Stirred solutions were left to equilibrate for $2 \mathrm{~h}$. Ultrapure water with resistivity $\geq 18 \mu \mathrm{S}$ $\mathrm{cm}^{-1}$ (Synergy UV purification system Millipore) was used in all preparations. The DGTs were deployed in solutions of $10^{-5} \mathrm{~mol} \cdot \mathrm{L}^{-1} \mathrm{Mg}, \mathrm{Ni}, \mathrm{Cu}$ and $\mathrm{Cd}$ (Fig 1) or $10^{-4} \mathrm{~mol} \cdot \mathrm{L}^{-1} \mathrm{Mg}$ (Figs 2 and 3), prepared from stocks of the corresponding nitrate metal salts $\left(\mathrm{Mg}\left(\mathrm{NO}_{3}\right)_{2} \cdot 6 \mathrm{H}_{2} \mathrm{O}, \mathrm{Cd}\left(\mathrm{NO}_{3}\right)_{2} \cdot 4 \mathrm{H}_{2} \mathrm{O}, \mathrm{Cu}\left(\mathrm{NO}_{3}\right)_{2} \cdot 3 \mathrm{H}_{2} \mathrm{O}\right.$, from Merck and $\mathrm{Ni}\left(\mathrm{NO}_{3}\right)_{2} \cdot 6 \mathrm{H}_{2} \mathrm{O}$ from Sigma-Aldrich).

The $\mathrm{pH}$ of the solution was adjusted to 6.5 or 7.5 by dropwise addition of $0.5 \mathrm{~mol} \cdot \mathrm{L}^{-1}$ $\mathrm{NaOH}$ (Merck) or $\mathrm{HNO}_{3}$ (Fluka) to a $5 \times 10^{-3} \mathrm{~mol} \cdot \mathrm{L}^{-1}$ MOPS (3-(N-morpholino)propanesulfonic acid, Sigma-Aldrich) pH-buffer, and accumulations were conducted at ionic strengths ranging from $5 \times 10^{-4}$ to $0.5 \mathrm{~mol} \cdot \mathrm{L}^{-1} \mathrm{NaNO}_{3}$ (Merk, Suprapur). For the experiments at the lowest ionic strength, only $2.5 \times 10^{-3} \mathrm{~mol} \cdot \mathrm{L}^{-1} \mathrm{MOPS}$ was used (without any other background salt). 
Deployment solutions and metal accumulations (once eluted in $\mathrm{HNO}_{3}$ ) were analyzed by ICP-MS. In order to obtain additional information on the spatial distribution of the accumulated Mg, DGT devices with 2 resin discs (2R) were used ${ }^{27}$ instead of the standard devices with one resin disc (1R). Separate elution and analysis of both resin discs, front (F) close to the diffusive gel or back (B) at the bottom of the sensor, were conducted.

\section{RESULTS AND DISCUSSION}

\section{Experimental accumulations and percentages of metal accumulated in the back resin disc}

Fig. 1 indicates a negligible influence of the ionic strength on the $\mathrm{Ni}, \mathrm{Cu}$ and $\mathrm{Cd}$ accumulations at $\mathrm{pH} 6.5$ which, plotted as $n_{\mathrm{M}} /\left(D_{\mathrm{M}} c_{\mathrm{M}}^{*}\right)$ vs. $I$, collapse. The mass percentage of these cations accumulated in the back resin disc (\%back) remains always lower than $5 \%$. These results indicate that the binding of $\mathrm{Ni}, \mathrm{Cu}$ and $\mathrm{Cd}$ is essentially independent of any change of the kinetic association constant $\left(k_{\mathrm{a}, \mathrm{R}}\right)$ and on the electrostatic partition concomitant with the ionic strength change. Instead, the binding of these cations proceeds under perfect-sink conditions. The average value of $n_{\mathrm{M}} /\left(D_{\mathrm{M}} c_{\mathrm{M}}^{*}\right)$ allows fitting the ratio $A / \delta^{g}$, which reaches a value of $0.36 \mathrm{~m}$, close to the result expected from the effective area, $3.80 \times 10^{-4} \mathrm{~m}^{2}$, and the thickness of the gel, filter and DBL, $8 \times 10^{-4}, 1.35 \times 10^{-4}$ and $1.15 \times 10^{-}$ ${ }^{4} \mathrm{~m}$, respectively ${ }^{19 ; 20}$.

Conversely, a strong increase of $\mathrm{Mg}$ accumulation is observed as ionic strength decreases in the range $0.5-0.01 \mathrm{~mol} \cdot \mathrm{L}^{-1}$. This increase goes parallel to a clear decrease of the \%back 
indicating that perfect-sink conditions only apply for the $\mathrm{Mg}$ binding at low enough ionic strength $\left(I<10^{-2} \mathrm{~mol} \mathrm{~L}^{-1}\right)$ as seen in Fig. 1 .

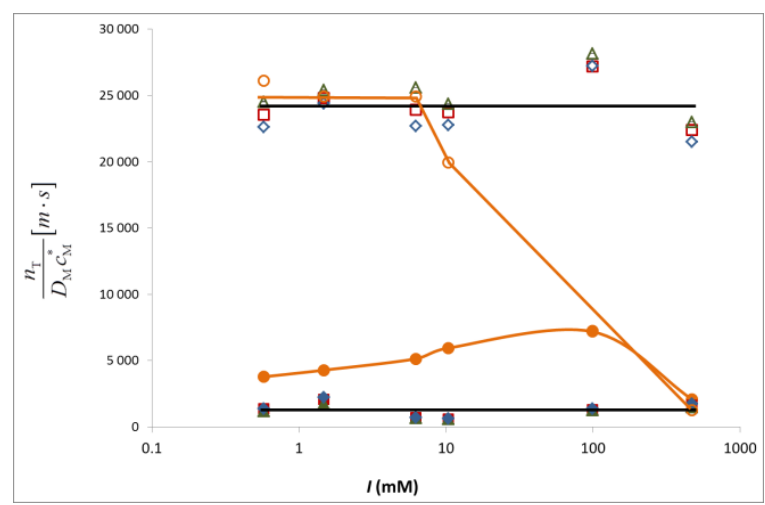

Figure 1. Normalized accumulation (accumulated moles over the bulk concentration and diffusion coefficient of each cation) of $\mathrm{Ni}$ (red square), $\mathrm{Cu}$ (green triangle), $\mathrm{Cd}$ (blue diamond) and $\mathrm{Mg}$ (orange bullet) in the front (open markers) and back (filled markers) resin discs in the range from $0.5 \times 10^{-3}$ to $0.5 \mathrm{~mol} \cdot \mathrm{L}^{-1}$. Experimental conditions: background electrolyte $\mathrm{NaNO}_{3}, \mathrm{pH} 6.5, c_{\mathrm{Mg}}^{*}=c_{\mathrm{Cd}}^{*}=c_{\mathrm{Cu}}^{*}=c_{\mathrm{Ni}}^{*}=10^{-5} \mathrm{~mol} \cdot \mathrm{L}^{-1}, \quad D_{\mathrm{Cd}}=6.30 \times 10^{-10}$ $\mathrm{m}^{2} \mathrm{~s}^{-1}, \quad D_{\mathrm{Cu}}=6.04 \times 10^{-10} \mathrm{~m}^{2} \mathrm{~s}^{-1}, \quad D_{\mathrm{Ni}}=6.08 \times 10^{-10} \mathrm{~m}^{2} \mathrm{~s}^{-1}, \quad D_{\mathrm{Mg}}=4.94 \times 10^{-10} \mathrm{~m}^{2} \mathrm{~s}^{-1}$ and $t=24 \mathrm{~h}$. Lines stand as a guide to the eye.

In order to have more information, a set of accumulation values for increasing times were recorded for each ionic strength in a series of additional experiments focussed on the binding of $\mathrm{Mg}$. The corresponding results are depicted as markers in Fig. 2. Clearly, $\mathrm{Mg}$ accumulations at high ionic strength are non linear. The non-linearity of accumulation with time indicates the absence of steady-state conditions due to the approaching to saturation or equilibrium conditions. While the accumulation at $48 \mathrm{~h}$ for $I=0.5 \mathrm{~mol} \cdot \mathrm{L}^{-1}$ is around 500 nmol, the accumulation raises up to $2500 \mathrm{nmol}$ for $I=10^{-2} \mathrm{~mol} \cdot \mathrm{L}^{-1}$ at $24 \mathrm{~h}$, so that the distortion of the linearity at high ionic strength is not due to saturation effects. Instead, accumulations close to equilibrium with the bulk $\mathrm{Mg}$ concentration are reached especially at $I=0.5 \mathrm{~mol} \cdot \mathrm{L}^{-1}$, and $t>25 \mathrm{~h}$, because the increase of the accumulation with time is almost negligible. We refer to this accumulation as thermodynamically limited. Under these 
conditions, the concentration of bound $\mathrm{Mg}$ is homogeneous all along the resin domain (which justifies that the \%back has raised up to 50\%) while the free $\mathrm{Mg}$ concentration in the resin domain reaches equilibrium with that in the bulk solution.

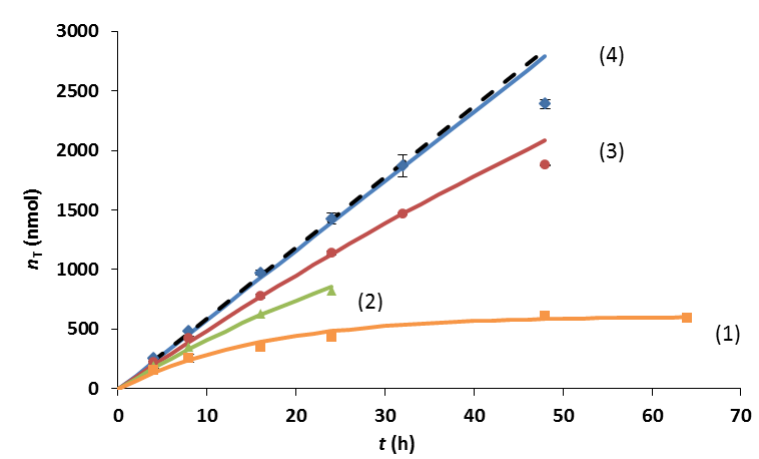

Figure 2. Time evolution of the total accumulation of $\mathrm{Mg}$ in DGT devices with two resin discs. Markers correspond to experimental accumulations at salt background concentrations of $0.5 \mathrm{~mol} \cdot \mathrm{L}^{-1}(1$, orange square), $0.1 \mathrm{~mol} \cdot \mathrm{L}^{-1}\left(2\right.$ green triangle), $0.05 \mathrm{~mol} \cdot \mathrm{L}^{-1}\left(3\right.$, red bullet) and $0.01 \mathrm{~mol} \cdot \mathrm{L}^{-1}(4$, blue diamond). Continuous lines correspond to the numerical simulation at $p H=7.5$ and the corresponding ionic strengths. Other parameters for the numerical simulations are listed in Table 2. Dashed line corresponds to Mg accumulation assuming to perfect-sink conditions.

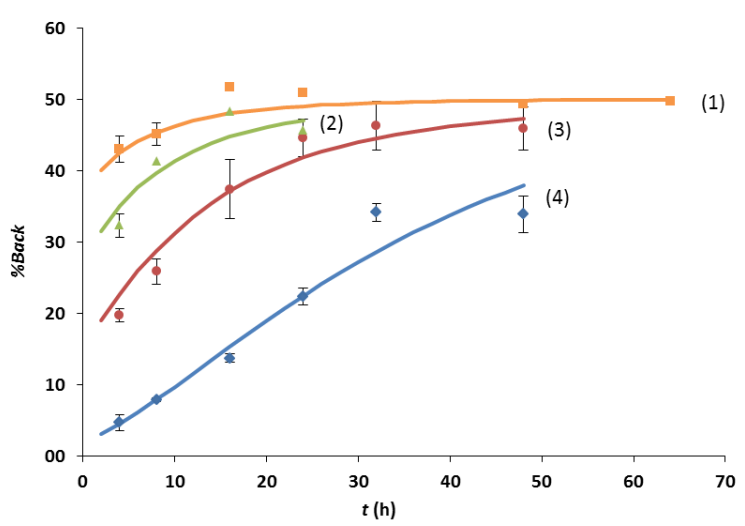

Figure 3. Percentage of Mg accumulated in the back resin disc. Markers and experimental conditions as in Fig. 2. Lines correspond to values predicted by numerical simulation.

The dependence of the stability constant of the $\mathrm{Mg}$ binding to the resin on the ionic strength is also clear in Fig. 2. This influence is responsible of the increase of the limiting bound $\mathrm{Mg}$ that would be obtained at long times for each ionic strength. 
Let us now concentrate on the limit of short times where $\mathrm{Mg}$ bound to the resin is expected to be far from the equilibrium concentration, but long enough to neglect transient effects ${ }^{27-}$ ${ }^{29}$. As seen in Fig. 2, the slope of the accumulation in the limit of short times depends on $I$. This dependence suggests that at short times, the accumulation does not follow perfect-sink conditions since this would imply a common slope for all ionic strengths. The different slopes point towards a dependence of the association rate constant on the ionic strength, but they could also reflect a faster accumulation due to an increasing partitioning of the metal at the resin-diffusive gel interface as the ionic strength decreases.

In the next Section, we outline two models to quantitatively describe the accumulations taking into account the phenomena discussed above.

\section{A model based on the Nernst-Planck equations}

Let us consider that $\mathrm{Mg}$ cations diffuse along the gel domain and penetrate into the resin where they bind to free resin sites $(\mathrm{R})$ to form occupied sites $(\mathrm{MgR})$ according to:

$$
\mathrm{Mg}+\mathrm{R} \underset{\mathrm{k}, \mathrm{R}}{\stackrel{k_{\mathrm{a}}}{\rightleftharpoons}} \mathrm{Mg} \mathrm{R}
$$

where charges are omitted for simplicity, and $k_{\mathrm{a}, \mathrm{R}}$ and $k_{\mathrm{d}, \mathrm{R}}$ are the association and dissociation rate constant of the binding process, respectively.

Resin sites are assumed to be immobile and homogeneously distributed in the resin disc. We neglect the settling of the Chelex beads during casting, because this effect is almost negligible in our system as it will be commented below ${ }^{30}$. This model neglects, then, the effects of the particulate nature of the resin beads, an approximation that can be justified when the diffusion layers around the beads overlap. Images obtained with an optical microscope of the resin disc lend support to this hypothesis. The main advantage of this 
model is a reduced computational cost, since it allows a 1-D simulation while the explicit consideration of the beads would require a 3-D simulation as well as a large set of parameters describing the position and structure of the beads and diffusion inside them. Due to these limitations, the kinetic constants $k_{\mathrm{a}, \mathrm{R}}$ and $k_{\mathrm{d}, \mathrm{R}}$ can be regarded as effective values that include the influence of diffusion and spatial heterogeneity of the binding sites on the rate of reaction with the Chelex particles. A detailed discussion of this effect to only one particle is given in ${ }^{31}$.

Since, at least at high ionic strength, the accumulation of $\mathrm{Mg}$ approaches equilibrium, the kinetics of both association and dissociation processes from the resin sites have to be considered in the model.

Additionally, since we are interested in analysing data corresponding to different ionic strengths, electrostatic effects due to the poor screening of the resin sites have also to be considered. As previously done ${ }^{21}$, we will assume that the electrostatic potential within the resin domain is determined by the charge of the resin sites and the background electrolyte $\left(\mathrm{NaNO}_{3}\right)$, i. e., $\mathrm{Mg}$ concentration is negligible compared to the background salt. A more detailed treatment of the electrostatic influence of the bead charges, modelled as soft particles, on the kinetics of the reaction with cations is given in ${ }^{32 ; 33}$. However, such treatment, for a dispersion of beads, requires 3-D mapping of the domain, as indicated above. As a first approximation, we restrict ourselves here to a mean field approximation. Considering that the transient regime is short in comparison to the deployment time, one can take a Donnan potential difference $\left(\Psi_{D}\right)$ at the interface between the resin and the gel phase, as a first approximation. The electroneutrality condition in the resin domain 
$-\frac{Q}{V_{\mathrm{R}}}+c_{\mathrm{Na}^{+}} e^{-F \Psi_{\mathrm{D}} / R T}-c_{\mathrm{NO}_{3}{ }^{-}} e^{F \Psi_{\mathrm{D}} / R T}=0$

allows the computation of the Donnan equilibrium potential difference between both phases as ${ }^{34}$,

$\Psi_{\mathrm{D}}=\frac{R T}{F} \arcsin \mathrm{h}\left(-\frac{Q}{2 V_{\mathrm{R}} I}\right)$

where $I$ indicates the ionic strength which can be approximated as $I=c_{\mathrm{Na}^{+}}=c_{\mathrm{NO}_{3}^{-}} \cdot Q$ are the moles of charged groups in the resin phase, $V_{\mathbf{R}}$ labels the volume of the resin domain, $F$ is the Faraday constant, $R$ stands for the universal gas constant and $T$ represents the temperature. Notice that, according to this expression the potential difference is only dependent on the concentration of the background salt. Under this approximation, the Donnan potential drop is considered to take place as a discontinuous potential jump across the resin-diffusive gel interface.

However, if this potential is calculated with the Poisson-Boltzmann equation, a continuous potential distribution is obtained. An analytical approximate expression for this potential dependence on the distance (when the fixed charges of the resin follow a Heaviside step function) is given by Ohshima ${ }^{35}$. This expression indicates that the potential is almost constant in both phases (Fig. S2 in the SI). The potential drop, given by Eqn. (3), takes place in a layer of thickness of the order of the Debye length located at the interface resingel. It could be argued that the distribution of the fixed charges is not so abrupt due to settling of the Chelex beads, and therefore, the influence of a thicker layer along which the potential changes will also be examined.

The Nernst-Plack model considers, then, that Mg is subjected to diffusion, migration and reaction with the resin sites. The corresponding set of equations, initial conditions, 
boundary values and details of the numerical solution are given in the SI. Matlab ${ }^{36}$ has been used for the numerical solution. This formulation holds independently of the ratio of the pertinent time scales of both steps, the transport to the resin domain given by $\left(\delta^{g}\right)^{2} / \pi D_{\mathrm{M}}$ and the association reaction given by $\left(k_{a, \mathrm{R}}^{\prime}\right)^{-1}$.

\section{The Partition model}

Additionally, since the thickness of the region where the potential changes is much smaller than the thickness of the resin domain (where the electrostatic potential is mostly constant), a model that summarizes the electrostatic effects in a partitioning factor at the resin-gel interface is also used. The numerical solution of this model has been carried out in Fortran as explained in the SI of ${ }^{30}$. The checking of the accuracy of such model is of interest because it allows finding approximate analytical expressions in some cases ${ }^{21}$.

Ions not consumed at the resin domain (i.e. sodium and nitrate) are expected to reach the equilibrium partitioning between the solution and the resin domain in a short transient time in comparison to the deployment time, so that their concentrations can be considered in equilibrium with the electrostatic potential along all the deployment time as a good approximation. Their concentration profiles will approach a discontinuity at the resin-gel interface determined by the Boltzmann factor, $\Pi$, which relates the concentrations at both sides of the interface (represented as $c_{i}^{r^{-}}$and $c_{i}^{r^{+}}$, respectively) 


$$
\Pi_{i}=\frac{c_{i}^{r^{-}}}{c_{i}^{r^{+}}}=\exp \left(-\frac{z_{i} F \Psi_{\mathrm{D}}}{R T}\right)
$$

However, for cations that react with the resin sites, this binding process can compete with the reaching of the Donnan equilibrium, so that the partitioning ruled by the Boltzmann factor can be seen as a limiting value corresponding to predominant electrostatic equilibrium. Notice that Donnan partitioning is strictly applicable only to species with a null flux (see details of this model in SI), although in many cases, accurate results can be obtained using the approximation of Eqn. (4).

\section{Boltzmann factors}

A small concentration of rubidium was added to the deployment solutions in order obtain an experimental measurement of the Boltzmann factor $\Pi_{\mathrm{Rb}}$. Rb was used as an alkaline cation whose specific binding to the Chelex is expected to be negligible. Thus, any $\mathrm{Rb}$ accumulation in the resin domain with respect to bulk concentration in the solution can be understood as due to the electrostatic partitioning. These values can be measured in the elution solution of the DGT resin disc. An additional confirmation of the Boltzmann factor can be obtained from the measurement of the $\mathrm{Na}$ concentration in the resin disc, since $\mathrm{Na}$ is another alkaline cation with almost negligible specific binding to Chelex. The ratio of the Rb concentration in the resin disc with respect to that in the gel domain yielded the $\Pi$ values reported in Table 1. Notice that we are assuming that the charge of the diffusive disc is negligible, so that $\mathrm{Rb}$ concentration in the diffusive gel is equal to that in the bulk solution. A similar procedure can be used with $\mathrm{Na}$ concentrations to find $\Pi_{\mathrm{Na}}$. The resulting values are reported in Table 1. 
Table 1 Boltzmann factor values, $\Pi$, estimated from eqn. (4) and from the experimental accumulations of $\mathrm{Rb}$ or $\mathrm{Na}$ at $\mathrm{pH}=7.5$.

\begin{tabular}{|c|c|c|c|}
\hline $\boldsymbol{I}(\mathbf{m M})$ & $\Pi$ & $\Pi_{\mathrm{Rb}}$ & $\Pi_{\mathrm{Na}}$ \\
\hline 10 & 5.77 & 5.84 & 5.71 \\
\hline 50 & 1.71 & 1.89 & 2.07 \\
\hline 100 & 1.32 & 1.27 & 1.36 \\
\hline 500 & 1.06 & 1.06 & 1.08 \\
\hline
\end{tabular}

Notice the agreement between the $\Pi$-values measured from $\mathrm{Rb}$ or $\mathrm{Na}$, which suggests that specific binding of $\mathrm{Na}$ is negligible at the range of concentrations and ionic strength here analysed $^{37}$ This agreement gives confidence to these measurements and indicates that the addition of $\mathrm{Rb}$ is a simple method to measure Boltzmann factors. As these factors are only dependent on $I$ and the charge of the resin, they can be applied to any system under the same conditions. A detailed compilation of these values for standard DGT devices could be of high interest for DGT users. Additionally, a value of $Q / V_{\mathrm{R}}=28 \mathrm{~mol} \cdot \mathrm{m}^{-3}$ fits the experimental $\Pi_{\mathrm{Rb}}$-values with Eqn. (4). The calculated $\Pi$-values are also reported in Table 1 showing a good agreement with the experimental measurements based on $\mathrm{Na}$ or $\mathrm{Rb}$ accumulations. Then, Eqn. (4) with $Q / V_{\mathrm{R}}=28 \mathrm{~mol} \cdot \mathrm{m}^{-3}$ can be used to estimate $\Pi$ for any ionic strength in the range $0.5-0.01 \mathrm{~mol} \cdot \mathrm{L}^{-1}$ and circumneutral $\mathrm{pH}$ as suggested by the well separated values of the Chelex acidity constants ${ }^{38}$. The fitted value of $Q / V_{\mathrm{R}}$ is somewhat lower than the one derived from the total number of functional groups and the mass of Chelex ${ }^{39}$ used in a resin disc due to the limitations of Eqn. (4) as well as to the uncertainty in the resin charge and resin volume.

\section{Fitting of $k_{\mathrm{a}, \mathrm{R}}$}

According to the above Section, the only adjustable parameters in the model are the rate constants of Eqn. (1). Their values were estimated from the simultaneous fit of the 
numerical models to both sets of experimental data ( $\mathrm{Mg}$ accumulation and \%back) shown in Fig. (2) and Fig. (3).

As both metal cation and resin sites have charges of opposite sign, increasingly attractive forces will arise between $\mathrm{Mg}$ and the resin sites, so that the kinetic association constant will increase as $I$ decreases. Thus, a fitted value of $k_{\mathrm{a}, \mathrm{R}}$ for each ionic strength has to be considered. As seen in Fig. 2, the bending of the accumulation line is especially important at $I=0.5 \mathrm{M}$, this indicating that the association rate is close to the dissociation rate, so that these data are the most sensitive to $k_{\mathrm{d}, \mathrm{R}}$. According to Eigen approach ${ }^{40 ; 41}$, the influence of the ionic strength only applies to the association kinetic constant, so that the value of $k_{\mathrm{d}, \mathrm{R}}$ fitted at $I=0.5 \mathrm{M}$ will be used for all ionic strength values considered. The increase of the association rate constant as $I$ decreases is then parallel to the increase of the stability constant since $K=k_{\mathrm{a}, \mathrm{R}} / k_{\mathrm{d}, \mathrm{R}}$.

The final values of the kinetic constants fitted with the Nernst-Planck model are reported in Table 2 and the agreement between predicted and measured accumulations can be seen in Fig. 2. The agreement is also quite reasonable in Fig. 3, especially if we consider the reproducibility of the experimental \%back measurements.

Table 2. Recovering of the kinetic association constant $k_{\mathrm{a}, \mathrm{R}}$ using a numerical simulation with experimental values of Boltzmann factor and $k_{\mathrm{d}, \mathrm{R}}=1.0 \times 10^{-4} \mathrm{~s}^{-1}$.

\begin{tabular}{|c|c|c|c|c|}
\hline $\begin{array}{c}\boldsymbol{I} \\
(\mathrm{mM})\end{array}$ & $\begin{array}{c}\boldsymbol{I}_{\mathbf{R}} \\
(\mathrm{mM})\end{array}$ & $\begin{array}{c}c_{\mathrm{Mg}}^{*} \\
\left(\mathrm{~mol} \mathrm{~m}^{-3}\right)\end{array}$ & $\begin{array}{c}\boldsymbol{K} \\
\left(\mathrm{m}^{3} \mathrm{~mol}^{-1}\right)\end{array}$ & $\begin{array}{c}\boldsymbol{k}_{\mathrm{a}, \mathbf{R}} \\
\left(\mathrm{m}^{3} \mathrm{~mol}^{-1} \mathrm{~s}^{-1}\right)\end{array}$ \\
\hline 10 & 30 & $9.2 \times 10^{-2}$ & 20.5 & $2.05 \times 10^{-3}$ \\
\hline 50 & 62 & $9.0 \times 10^{-2}$ & 4.4 & $4.4 \times 10^{-4}$ \\
\hline 100 & 108 & $9.0 \times 10^{-2}$ & 1.7 & $1.7 \times 10^{-4}$ \\
\hline 500 & 500 & $9.3 \times 10^{-2}$ & 0.7 & $7.0 \times 10^{-5}$ \\
\hline
\end{tabular}


The values of the kinetic constants reported in Table 2 are used in the simulation tool developed with the Partition model. In that case, partition factors $\Pi_{\mathrm{Mg}}=\Pi_{\mathrm{Rb}}^{2}$ are used at each ionic strength according to the $\Pi_{\mathrm{Rb}}$ values reported in Table 1. The accumulation and \%back merge perfectly with those reported in Figs. 2 and 3.

As seen in Table S-1, the thickness of the potential transition layer (whenever it is lower than $10^{-5} \mathrm{~m}$ ) has very little impact on the $\mathrm{Mg}$ accumulations calculated with the fitted kinetic constants. However, the concentration profile of free $\mathrm{Mg}$ ions does actually depend on the thickness of this layer and the slope of the potential at the resin-gel interface (data not shown). This can be explained as follows. In steady-state conditions, the metal profile is linear in the diffusive gel region away from the transition layer. But close to the gel-resin interface, where migration effects take place, the electrical influence is compensated by a reduction in the slope of the concentration profile to keep the flux constant. When the electrical influence is high enough (the electrical force is proportional to the slope of the electrostatic potential) the slope of the $\mathrm{Mg}$ concentration profile reverses its sign. The limiting case is the electrostatic potential discontinuity (Donnan model).

Notice that $\Pi_{\mathrm{Mg}}$ increases with decreasing $I$, indicating a tendency of the free $\mathrm{Mg}$ concentration to build up in the resin domain to achieve electrostatic equilibrium consistent with the potential drop at the resin-gel interface. This effect has a negligible influence on the \%back, as supported by the numerical simulation results (data not shown). Thus, the decrease of the \%back as the ionic strength decreases is an evidence of the increase of the kinetic association and of the stability constants, which reduces the penetration of the $\mathrm{Mg}$ in the resin domain by accelerating the reaction with the resin sites and increases the "capacity" of the resin. 
It seems also interesting to discuss the relative importance of the "territorial" (i.e., purely electrostatic) and specific binding mechanisms in the overall metal accumulation. Accumulations depicted in Fig 2 are split in Table S2 of the SI into two fractions, namely: the moles of free $\mathrm{Mg}^{2+}$ ions (within the resin volume) and the moles of $\mathrm{Mg}$ chemically bound. As can be seen, the amount of free $\mathrm{Mg}$ is, at any $I$, negligible in comparison to the amount of $\mathrm{Mg}$ specifically bound to the resin groups. Notice also that, in contrast to what is expected from equilibrium arguments, the amount of free $\mathrm{Mg}$ accumulated in the resin disc decreases as ionic strength decreases, indicating that equilibrium conditions are far to be reached since the system has approached perfect sink conditions. However, the electrostatic effects are not only responsible for the territorial accumulation, but also for an increase of the accumulation due to a faster transport. This influence can be estimated by just comparing the total accumulation with the hypothetical accumulation calculated with $\Pi_{\mathrm{Mg}}$ $=1$ (i.e., without electrostatic partitioning), as reported in Table S2. For a $24 \mathrm{~h}$ deployment, the influence of the electrostatic partitioning is similar in all the range of ionic strengths and remains around $22 \%$ at the lowest $I$. Under the conditions of this work, the increase of the association rate constant (and that of the corresponding equilibrium value) is, then, the most relevant phenomena responsible for the increase of $\mathrm{Mg}$ accumulation as $I$ decreases.

\section{Dependence of $k_{\mathrm{a}, \mathrm{R}}$ on the ionic strength}

Kinetic salt effects for simple ions are described by the Bjerrum theory. This theory explains the ionic strength dependence of the rate constants as due to the dependence of the activities of the reactants in the salt medium. Debye Hückel expressions, or other extensions, can be used for the activity coefficients depending on the salt concentration. 
The application of this theory to the current case deserves two comments: i) the fitted association rate constant values correspond to the ionic strength in the resin domain $I_{\mathrm{R}}$ (which differs from that in the solution due to the electrostatic partitioning at the resin gel interface of the background ions); ii) the resin site is not a chemical species but it is embedded in a bead of Chelex with many functional groups. Accordingly, Bjerrum expression could be seen as a first approach to describe the dependence of the fitted $k_{\mathrm{a}, \mathrm{R}}$ on I. In any case, resin beads interact with the $\mathrm{Mg}$ cations, which will feel an "effective" charge that will reflect, not only the charge of the carboxylic and amino functional groups where $\mathrm{Mg}$ gets bound, but the total electrical interaction between $\mathrm{Mg}$ and all the charges of the resin bead at their respective distances. Assuming that the Davies model can be used for the activity coefficients, and labelling as $z_{\mathrm{R}}$ the "effective" charge felt by the metal cation due to the resin site, the dependence of the association rate constant on the ionic strength can be written as

$\log k_{\mathrm{a}, \mathrm{R}}=\log k_{\mathrm{a}, \mathrm{R}}^{\infty}+1.02 z_{\mathrm{Mg}} z_{\mathrm{R}}\left(\frac{\sqrt{I_{\mathrm{R}}}}{1+\sqrt{I_{\mathrm{R}}}}-0.3 I_{\mathrm{R}}\right)$

where $k_{\mathrm{a}, \mathrm{R}}^{\infty}$ corresponds to the limiting rate constant when ionic strength tends to zero.

From the $\Pi$-values reported in Table 1, the ionic strength in the resin domain, $I_{\mathrm{R}}$, can be computed as:

$I_{\mathrm{R}}=\frac{1}{2}\left(\Pi c_{\mathrm{Na}}^{*}+\frac{1}{\Pi} c_{\mathrm{NO}_{3}^{-}}^{*}\right)=\frac{1}{2} c_{\mathrm{Na}}^{*}\left(\Pi+\frac{1}{\Pi}\right)$

The fitting of the $k_{\mathrm{a}, \mathrm{R}}$ values reported in Table 2 to Eqn. (5) is seen in Fig 4. 


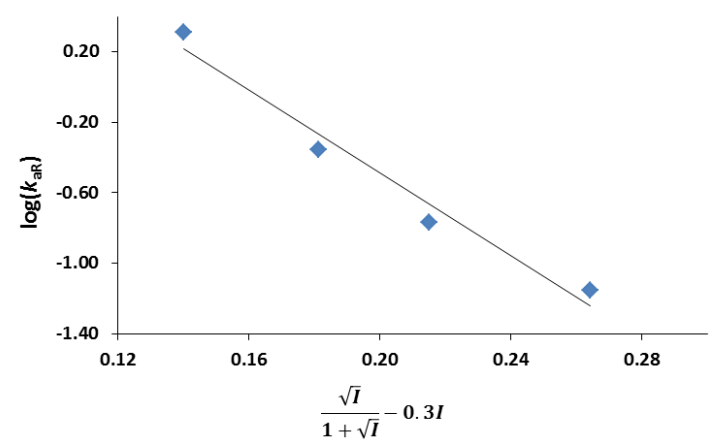

Figure 4. Dependence of the association rate constant of $M g$ to the Chelex beads of the DGT resin disk on the ionic strength (inside the resin) $I_{\mathbf{R}}$.

As can be seen, a good agreement between the experimental results and the Bjerrum equation arises when $\log k_{\mathrm{a}, \mathrm{R}}^{\infty}=1.86, z_{\mathrm{Mg}}=+2$ and $z_{\mathrm{R}}=-5.7$, which indicates that $\mathrm{Mg}$ cations experience an effective charge of -5.7 resultant from the resin sites. This high value indicates a strong influence of the ionic strength on the association rate constant. Moreover, Eqn. (5) can be used to predict the kinetic association constant at any ionic strength within the range studied. In combination with the Boltzmann factors predicted with Eqns. (3-4), the model allows the theoretical calculation of $\mathrm{Mg}$ availability to standard DGT devices.

\section{CONCLUSIONS}

This work has shown that $\mathrm{Mg}$ accumulation in high ionic strength solutions is thermodynamically limited by $\mathrm{Mg}$ binding to the resin at $\mathrm{pH}$ 7.5. However, as ionic strength decreases, the thermodynamic limitation is less severe due to the increase of the stability and kinetic association constants. This is the main phenomenon that increases $\mathrm{Mg}$ 
availability. The electrostatic partitioning arising at the resin-diffusive gel interface, which can be determined by adding to the system a small concentration of $\mathrm{Rb}$, has a smaller influence on $\mathrm{Mg}$ accumulation.

Some practical guidelines can be derived from the simulation tools and fitted constants of this work. For freshwaters, with a typical ionic strength of $10 \mathrm{mM}$, accumulation of $\mathrm{Mg}$ in a standard DGT device with only one resin disc follows perfect sink conditions (with deviations of the accumulation of less than 5\%) during at least 72 hours deployment, whenever the $\mathrm{Mg}$ concentration is below $0.1 \mathrm{mM}$. When $\mathrm{Mg}$ concentration increases up to $0.5 \mathrm{mM}$, perfect-sink conditions apply until $17 \mathrm{~h}$ and when $\mathrm{Mg}$ concentration increases up to $1 \mathrm{mM}$, perfect sink conditions can be applied until $9 \mathrm{~h}$ deployment. For a more complete set of values including $10 \%$ deviations, see Table S3 in the SI. For seawaters, typical ionic strength $0.5 \mathrm{M}$, the perfect-sink assumption is not appropriate, regardless the deployment time.

Other $\mathrm{pH}$ values can modify the charge of the resin domain via acid-base equilibria. However, due to the large difference in the $\mathrm{pK}_{\mathrm{a}}$ values of the Chelex groups, values of $k_{\mathrm{a}, \mathrm{R}}$ and $\Pi_{i}$ predicted with Eqns. (5) and (3-4), respectively, are expected to be valid in the range of $\mathrm{pH}$ of natural waters.

Similar principles are expected to be useful for $\mathrm{Ca}$ accumulations, and help in the understanding of major cations availability in natural waters.

\section{ASSOCIATED CONTENT}

Supporting Information 
Additional information as noted in the text. This material is available free of charge via the Internet at http://pubs.acs.org.

\section{ACKNOWLEDGMENTS}

Financial support from FEDER and the Spanish Ministry of Education and Science (Projects CTM2012-39183 and CTM2013-48967) is gratefully acknowledged.

\section{REFERENCES}

1. Emerson, W. W.; Smith, B. H. Nature 1970, 228, 453-\&.

2. Indarawis, K.; Boyer, T. H. Environmental Science \& Technology 2012, 46, 4591-98.

3. Wang, L. F.; He, D. Q.; Chen, W.; Yu, H. Q. Water.Res. 2015, 81, 325-32.

4. Fujii, M.; Yeung, A. C. Y.; Waite, T. D. Environmental Science \& Technology 2015, 49, 9133-42.

5. Chaigne-Delalande, B.; Li, F. Y.; O'Connor, G. M.; Lukacs, M. J.; Jiang, P.; Zheng, L.; Shatzer, A.; Biancalana, M.; Pittaluga, S.; Matthews, H. F.; Jancel, T. J.; Bleesing, J. J.; Marsh, R. A.; Kuijpers, T. W.; Nichols, K. E.; Lucas, C. L.; Nagpal, S.; Mehmet, H.; Su, H. C.; Cohen, J. I.; Uzel, G.; Lenardo, M. J. Science 2013, 341, 186-91.

6. Davies, B. E. Environmental Geochemistry and Health 2015, 37, 411-27.

7. Yan, M. Q.; Lu, Y. J.; Gao, Y.; Benedetti, M. F.; Korshin, G. V. Environmental Science \& Technology 2015, 49, 8323-29.

8. Guskov, A.; Nordin, N.; Reynaud, A.; Engman, H.; Lundback, A. K.; Jong, A. J. O.; Cornvik, T.; Phua, T.; Eshaghi, S. Proceedings of the National Academy of Sciences of the United States of America 2012, 109, 18459-64.

9. Ferreira, D.; Ciffroy, P.; Tusseau-Vuillemin, M. H.; Bourgeault, A.; Gamier, J. M. Chemosphere 2013, 91, 241-47.

10. Ardestani, M. M.; van Straalen, N. M.; van Gestel, C. A. M. Environ.Toxicol.Chem. 2015, 34, 2194-204. 
11. Markich, S. J. Sci.Total Envir. 2013, 443, 582-89.

12. Juang, K. W.; Lee, Y. I.; Lai, H. Y.; Chen, B. C. Ecotox.Environ.Safe. 2014, 104, 3642.

13. Zhang, H.; Davison, W. Anal.Chem. 1995, 67, 3391-400.

14. Bennett, W. W.; Teasdale, P. R.; Panther, J. G.; Welsh, D. T.; Jolley, D. F. Anal.Chem. 2010, 82, 7401-07.

15. Panther, J. G.; Teasdale, P. R.; Bennett, W. W.; Welsh, D. T.; Zhao, H. J. Environ.Sci.Technol. 2010, 44, 9419-24.

16. Davison, W.; Zhang, H. Environ.Chem. 2012, 9, 1-13.

17. Dahlqvist, R.; Zhang, H.; Ingri, J.; Davison, W. Analytica Chimica Acta 2002, 460, 247-56.

18. Garmo, O. A.; Royset, O.; Steinnes, E.; Flaten, T. P. Anal.Chem. 2003, 75, 3573-80.

19. Peters, A. J.; Zhang, H.; Davison, W. Anal.Chim.Acta 2003, 478, 237-44.

20. Warnken, K. W.; Zhang, H.; Davison, W. Anal.Chem. 2005, 77, 5440-46.

21. Puy, J.; Galceran, J.; Cruz-Gonzalez, S.; David, C. A.; Uribe, R.; Lin, C.; Zhang, H.; Davison, W. Analytical Chemistry 2014, 86, 7740-48.

22. Alfaro-De la Torre, M.; Beaulieu, P. Y.; Tessier, A. Anal.Chim.Acta 2000, 418, 5368.

23. Yezek, L. P.; van Leeuwen, H. P. Langmuir 2005, 21, 10342-47.

24. Yezek, L. P.; van der Veeken, P. L. R.; van Leeuwen, H. P. Environ.Sci.Technol. 2008, 42, 9250-54.

25. van der Veeken, P. L. R.; Pinheiro, J. P.; van Leeuwen, H. P. Environ.Sci.Technol. 2008, 42, 8835-40.

26. Levy, J. L.; Zhang, H.; Davison, W.; Puy, J.; Galceran, J. Anal.Chim.Acta 2012, 717, 143-50.

27. Galceran, J.; Puy, J. Environ.Chem. 2015, 12, 112-22.

28. Mongin, S.; Uribe, R.; Rey-Castro, C.; Cecilia, J.; Galceran, J.; Puy, J. Environ.Sci.Technol. 2013, 47, 10438-45.

29. In Situ Monitoring of Aquatic Systems. Chemical Analysis and Speciation. IUPAC Series on Analytical and Physical Chemistry of Environmental Systems., John Wiley \& Sons: Chichester, 2000. 
30. Jimenez-Piedrahita, M.; Altier, A.; Cecilia, J.; Rey-Castro, C.; Galceran, J.; Puy, J. Anal.Chim.Acta 2015, 885, 148-55.

31. Pinheiro, J. P.; Minor, M.; van Leeuwen, H. P. Langmuir 2005, 21, 8635-42.

32. Duval, J. F. L.; van Leeuwen, H. P. J.Phys.Chem.A 2012, 116, 6443-51.

33. Town, R. M.; Buffle, J.; Duval, J. F. L.; van Leeuwen, H. P. J.Phys.Chem.A 2013, 117, 7643-54.

34. Companys, E.; Garcés, J. L.; Salvador, J.; Galceran, J.; Puy, J.; Mas, F. Colloids Surf.A 2007, 306, 2-13.

35. Ohshima, H.; Ohki, S. Biophys.J. 1985, 47, 673-78.

36. MATLAB Release 2012b, the MathWorks Inc., Natick, Massachusetts, United States.

37. Berto, S.; Daniele, P. G.; Lando, G.; Prenesti, E.; Sammartano, S. International Journal of Electrochemical Science 2012, 7, 10976-86.

38. Pesavento, M.; Biesuz, R.; Baffi, F.; Gnecco, C. Anal.Chim.Acta 1999, 401, 265-76.

39. Chelex® 100 and Chelex 20 Chelating Ion Exchange Resin Instruction Manual. 2013. Bio-Rad Laboratories.

Ref Type: Online Source

40. Eigen, M.; Wilkins, R. The Kinetics and Mechanism of Formation of Metal Complexes, 49 ed.; American Chemical Society: Washington, 1965.

41. Morel, F. M. M.; Hering, J. G. Principles and Applications of Aquatic Chemistry, John Wiley: New York, 1993; Chapter 6. 